\title{
Short communication: Amino acid supplementation and stage of lactation alter apparent utilization of nutrients by blood neutrophils from lactating dairy cows in vitro
}

\author{
M. Garcia, ${ }^{*}$ T. H. Elsasser,† L. Juengst, ${ }^{*}$ Y. Qu, ${ }^{*}$ B. J. Bequette, ${ }^{* 1}$ and K. M. Moyes ${ }^{* 2}$ \\ *Department of Animal and Avian Sciences, University of Maryland, College Park 20740 \\ †Agricultural Research Service, Animal Biosciences and Biotechnology Laboratory, USDA, Beltsville, MD 20705
}

\begin{abstract}
Glutamine is the preferred AA used by polymorphonuclear leukocytes (PMN) during the inflammatory response. However, the effect of other AA on bovine PMN response during inflammation and how this is altered by stage of lactation has not been fully elucidated. The objective of this study was to determine the effect of additional AA supplementation (pool of AA excluding Gln) on AA profiles, gene expression, and inflammatory function of PMN from dairy cows in early and mid lactation in vitro. We used 18 Holstein cows for this study. Polymorphonuclear leukocytes were isolated. Working solutions of AA (0 or $4 \mathrm{mM})$ and LPS $(0$ or $50 \mu \mathrm{g} / \mathrm{mL}$ ) were added to cell populations suspended in RPMI and incubated for $2 \mathrm{~h}$ at $37^{\circ} \mathrm{C}$. We used a subset of samples for gene and protein expression. Concentrations of AA in medium were determined using gas chromatography-mass spectrometry with norleucine as an internal standard. Apparent AA and glucose utilization were calculated by subtracting the concentration after from that of before incubation. Data were analyzed as a randomized block design. Challenge with LPS increased the expression of proinflammatory genes and AA supplementation decreased both the expression of some proinflammatory genes and the media concentrations of tumor necrosis factor- $\alpha$. Neither stage of lactation, LPS challenge, nor AA supplementation altered the chemotactic or phagocytic abilities of PMN in vitro. Polymorphonuclear leukocytes supplemented with AA had greater concentrations and apparent utilization of most of the supplemented AA, whereas the unsupplemented group had greater apparent utilization of glucose. Alanine was not provided in the media but was present in spent media, and Ile, Gly, and Pro were greater in spent media than in media before
\end{abstract}

Received July 8, 2015.

Accepted January 22, 2016.

${ }^{1}$ Deceased.

${ }^{2}$ Corresponding author: kmoyes@umd.edu incubation indicating synthesis of these AA. Regarding expression of genes involved in nutrient metabolism, the expression of $G 6 P D$, coding for the enzyme glucose 6-phosphate dehydrogenase, was increased and that of PDHA1, coding for the enzyme pyruvate dehydrogenase $\alpha 1$, tended to increase with AA supplementation. Due to the lower concentration of tumor necrosis factor- $\alpha$ in media coupled with a downregulation of several proinflammatory genes, we concluded that AA, rather than Gln, alter the inflammatory response of bovine blood PMN. Independent from Gln, blood PMN from cows in early lactation may use certain AA as their primary carbon source for energy than cows in later lactation. Evaluating cows during the early postpartum period will provide additional information on the effect of stage of lactation and nutrient supplementation on PMN function.

Key words: amino acids, inflammation, lactating cows, neutrophils

\section{Short Communication}

During mastitis, circulating PMN are of key importance in controlling the severity and duration of mastitis, accounting for approximately $95 \%$ of somatic cell population in milk (Kehrli and Shuster, 1994; Burvenich et al., 2007). Due to natural immunosuppression, as well as changes in the hormonal, neurological, metabolic, and digestive systems, cows in early lactation are at a greater risk for the development of diseases, especially mastitis, when compared with any other stage of lactation (Ingvartsen, 2006). Concentrations of most AA in plasma are relatively constant throughout pregnancy and lactation; however, AA can undergo drastic changes around the time of parturition (Meijer et al., 1995; Maeda et al., 2012), during periods of malnutrition (Weekes et al., 2006), and during off-feed situations such as during clinical disease (Hailemariam et al., 2014). Li et al. (2007) reviewed and described the critical proinflammatory roles of Gln and Arg and the potential anti-inflammatory or immunoregulatory 
effects of Gly and Tyr on PMN response from humans and animal models in vitro. More recently, studies have documented the inflammatory effect of Arg and or Gln in some livestock species (Tan et al., 2009; Perez-Carbajal et al., 2010; Pohlenz et al., 2012). Even though the role of Gln on PMN response has been well documented, research concerning supplementation of other AA on bovine PMN response is scarce. Furthermore, little information is available regarding how this response may differ based on stage of lactation. Hence, the objective of our study was to determine the effect of a pool of additional AA on bovine blood PMN response and how this response differs for cows in early and mid lactation.

All procedures involving the use of live animals were approved in accordance with the regulations and guidelines set forth by the USDSA Beltsville Animal Care and Use Committee. Thirteen primiparous and 5 multiparous ( $\geq 2$ lactations) Holstein cows in early $(\mathrm{n}=9$; $\mathrm{DIM}=17 \pm 3.2 ; 34.0 \mathrm{~kg}$ of milk/d) and mid lactation $(\mathrm{n}=9 ; \mathrm{DIM}=165 \pm 14.4 ; 38.6 \mathrm{~kg}$ of milk/d) were used for this study. Details regarding animal selection, housing, management, isolation of PMN, and analysis are described in Garcia et al. (2015b). Jugular blood $(\sim 150 \mathrm{~mL})$ was collected from cows in early and mid lactation. For each cow, isolated PMN were adjusted to desired concentrations for phagocytosis $\left(2 \times 10^{6}\right.$ cells/ $\mathrm{mL})$, chemotaxis $\left(3 \times 10^{6}\right.$ cells $\left./ \mathrm{mL}\right)$, gene expression $(6$ $\times 10^{6}$ cells $\left./ \mathrm{mL}\right)$, and media analyses $\left(6 \times 10^{6}\right.$ cells $\left./ \mathrm{mL}\right)$ using RPMI 1640 without Gln (R0883, Sigma-Aldrich Co., St. Louis, MO) containing $5 \%$ heat-inactivated fetal bovine serum (Sigma-Aldrich Co.). Cell populations were incubated for $2 \mathrm{~h}$ at $37^{\circ} \mathrm{C}, 95 \%$ relative humidity, and $5 \% \mathrm{CO}_{2}$ with additional $\mathrm{AA}$ supplementation (AAS; RPMI 1640 50X; catalog number R7131; SigmaAldrich Co.) or without additional AA (PBS, control; CTL). For gene expression and media analyses only, we transferred tubes to a sterile hood where LPS (50 $\mu \mathrm{g} / \mathrm{mL}$ final concentration; L055; Sigma Aldrich Co.) or no LPS (i.e., PBS) was added. Lipopolysaccharide was used based on previous experiments (Revelo and Waldron, 2012; Garcia et al., 2015b). The addition of $4 \mathrm{~m} M$ of a pool of AA were supplemented in the AAS treatment at $\sim 2$ times that of physiological concentration (Meijer et al., 1995) and equivalent to doses used in our laboratory (Garcia et al., 2015b). Final concentrations of AA were 3.1 and $7.1 \mathrm{mM}$ for the CTL and AAS groups, respectively (details of individual AA are presented in Supplemental Table S1; http://dx.doi. org/10.3168/jds.2015-10086). After incubation, we analyzed PMN for gene expression. Isolation of RNA, quality evaluation, cDNA synthesis, primer selection and design sequence, efficiency of dilution, and real-time quantitative PCR analysis were as previously described
(Garcia et al., 2015b). Additional primer sequence and efficiency of dilution curves for $B C K D H B$ is presented in Supplemental Tables S2 and S3, respectively (http:// dx.doi.org/10.3168/jds.2015-10086). Concentrations of tumor necrosis factor- $\alpha$ (TNF- $\alpha)$ in the media and concentrations of serum, media metabolites [i.e., nonesterified fatty acids (NEFA), BHB, and glucose], PMN chemotaxis, and phagocytosis capabilities were assessed as described elsewhere (Garcia et al., 2015a).

Spent media $(200 \mu \mathrm{L})$ and 6 different volumes of AA standard (AAS18; Sigma-Aldrich Co.) were weighed into a $\mathrm{V}$-vial and $30 \mathrm{uL}$ (weight recorded) of the internal standard L-norleucine ( $5 \mathrm{mM}$, Sigma-Aldrich Co.) were added. The $\mathrm{V}$-vials were dried under $\mathrm{N}_{2}$. Amino acids were converted to their tert-butyldimethyl-silyl using a $1: 1$ (vol/vol) mixture of N-methyl-N-[tert-butyldimethyl-silyl]trifuoroacetimide (United Chemical Technologies Inc., Bristol, PA) and dimethylformamide (Thermo Scientific, Rockford, IL). After heating via a microwave (200 W for $2 \mathrm{~min}$ ), the AA-tert-butyldimethyl-silyl derivatives were separated by GC-MS (HP 5973N Mass Selective Detector, Agilent, Palo Alto, CA). A fragment containing $\mathrm{C}_{12}$ ion of an analyte was monitored under electron impact mode. For AA quantification, the peak area for each AA in spent media and in the 6-series of AAS18 were adjusted by the actual weight of samples and a peak area ratio was generated by dividing the adjusted peak area of a given AA by the adjusted peak area of L-norleucine. We calculated AA concentrations with calibration curves obtained by plotting the peak area ratio of a given AA in the AAS18 standard against known concentrations of AA. Apparent glucose and AA utilization were estimated according to Healy et al. (2002). Briefly, the amount of glucose or AA taken up by PMN was obtained by subtracting the after incubation concentration from the before incubation concentration. To clarify, negative values for AA represent release of AA by PMN into the media.

For AA concentration and gene expression, we used a subset of samples for statistical analysis. The data were analyzed using the PROC MIXED procedure of SAS (SAS Institute, 2009). The data were tested for normality and presence of outliers and were analyzed as a randomized block design. Separation of LSM and individual comparisons for significant effects were performed using the PDIFF statement in SAS. Delta quantification cycle $(\Delta \mathrm{Cq})$ values were obtained by subtracting the $\mathrm{Cq}$ value of target genes by the $\mathrm{Cq}$ value of the geometric mean of 2 endogenous controls ( $R S P 9$ and $O S B P L)$, the $\triangle \mathrm{Cq}$ values without transformation were subjected to statistical analysis. For gene expression, we calculated fold-change $(\mathbf{F C})$ values according to Livak and Schmittgen (2001). Briefly, LSM ( $\Delta$ Cq) of a factor of interest was subtracted from the LSM 
$(\Delta \mathrm{Cq})$ of other referential factor to generate the $\Delta \Delta \mathrm{Cq}$ value, which was linearized to a $\mathrm{FC}$ (i.e., AAS vs. CTL, LPS vs. no LPS) value with the formula $2^{-\Delta \Delta \mathrm{Cq}}$. The LSM and SEM are presented in tables and figures.

Concentrations of serum BHB tended $(P=0.08)$ to be greater for cows in early $(5.38 \pm 0.53 \mathrm{mg} / \mathrm{dL})$ than for cows in mid lactation $(3.96 \pm 0.53 \mathrm{mg} / \mathrm{dL})$. Similarly, concentrations of serum NEFA were $\sim 2$ times greater $(P=0.03)$ for cows in early $(0.57 \pm 0.09$ $\mathrm{mEq} / \mathrm{L})$ than mid lactation $(0.27 \pm 0.09 \mathrm{mEq} / \mathrm{L})$. Serum glucose concentrations did not differ $(P=0.34)$ by stage of lactation, at 58.4 and $61.8 \pm 2.4 \mathrm{mg} / \mathrm{dL}$ for cows in early and mid lactation, respectively. Although concentrations of BHB and NEFA were greater for cows in early than mid lactation, these concentrations were below defined critical threshold values $(>10 \mathrm{mg} / \mathrm{dL}$ and $>0.6$ to $1.0 \mathrm{mEq} / \mathrm{L}$, respectively) predicting risk of different diseases during the first 2 wk of lactation (Ospina et al., 2010; Chapinal et al., 2012). Hence, the metabolic profile of cows in early lactation ( $\sim 17$ DIM) in the current study may indicate that these cows were not as metabolically challenged as early postpartal cows (Graugnard et al., 2012). This metabolic profile may partly explain the lack of effect of stage of lactation on chemotaxis (69.2 vs. $66.7 \pm 14.8$ cells migrating for CTL and AAS, respectively, $P=0.78$ ), phagocytosis (37.6 vs. $34.8 \pm 4.4 \%$ for CTL and AAS, respectively, $P$ $=0.15)$, and media concentrations of TNF- $\alpha$. A lack of stage of lactation effect was also observed in the expression of genes coding for inflammatory PMN receptors, signaling factors, cytokines, enzymes, and receptors involved in glucose and AA metabolism (for a complete list of genes and their effects see Supplemental Table S4; http://dx.doi.org/10.3168/jds.2015-10086). In a recent paper (Garcia et al., 2015b) we also observed that stage of lactation did not alter PMN function and minimal differences in gene expression were observed after glucose supplementation.

The concentration of several AA (Table 1) was lower and apparent utilization was greater (Supplemental Table S5; http://dx.doi.org/10.3168/jds.2015-10086) for cows in early when compared with cows in mid lactation. Specifically, concentrations of Lys, Met, Thr, Arg, Asn, Glu, and Ser were lower $(P \leq 0.03)$ for cows in early compared with mid lactation. This response reflected a greater apparent utilization of these AA for cows in early lactation. Although increased AA availability in blood may result in increased mammary uptake for the synthesis of milk components, our results indicate that blood PMN from cows in early lactation may use more carbons from AA than cows in mid lactation. However, stage of lactation did not alter the expression of key genes involved in AA and glucose metabolism (Supplemental Table S4; http:// dx.doi.org/10.3168/jds.2015-10086), suggesting that post-translational modifications may better explain the utilization of AA by blood PMN.

The interaction of AA $\times$ stage of lactation is shown in Table 2 and the corresponding apparent AA utilization can be found in Supplemental Table S6 (http://

Table 1. Effect of AA supplementation and LPS challenge in vitro ${ }^{1}$ on the concentration of AA in media $(\mu M)$ from PMN from Holstein cows in early $(\mathrm{n}=6)$ or midlactation $(\mathrm{n}=6)$

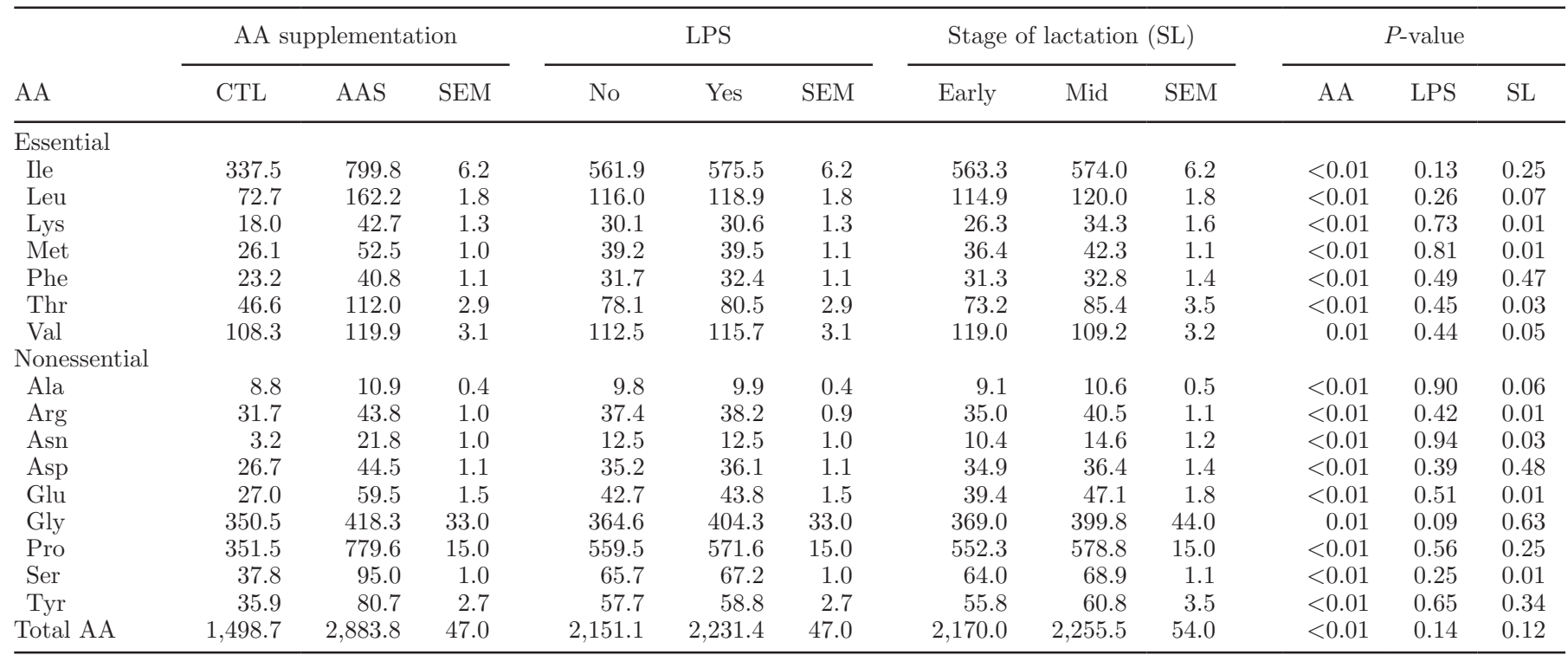

${ }^{1}$ Additional AA supplementation: CTL (no additional AA) or AAS (4 $\mathrm{m} M$ of a pool of additional AA without Gln) and LPS challenge: No LPS $(0 \mu \mathrm{g} / \mathrm{mL}$ of culture media) or LPS $(50 \mu \mathrm{g} / \mathrm{mL}$ of culture media) incubated for $2 \mathrm{~h}$. 
dx.doi.org/10.3168/jds.2015-10086). Within the AAS group the concentrations of 3 EAA (Lys, Met, and Thr) and 3 nonessential AA (Arg, Asn, and Glu) were lower, whereas the utilization was greater from cows in early compared with cows in mid lactation in bovine blood PMN. This provides additional evidence that PMN from cows in early lactation may increase the utilization of these AA when compared with cows in mid lactation. This effect was independent of inflammation (i.e., LPS). Studies involving the metabolism of nutrients by bovine immune cells are limited. In leukocytes, primarily monocytes and lymphocytes, the majority of carbons originating from glucose enter the pentose phosphate pathway for the generation of reducing equivalents for phagocytosis or are converted to lactate during anaerobic glycolysis (Moyes, 2015). Thus, leukocytes use carbons donated from AA, primarily Gln, for the generation of energy via the Krebs cycle. Our results suggest that bovine blood PMN from cows in early lactation use more AA carbons than cows in mid lactation, thus sparing the limited amount of glucose observed for cows in early lactation for other biological functions. However, whether the development of mastitis and or the partitioning of nutrients to other tissues, such as the mammary gland and the liver, alter this response is currently unknown and additional in vivo studies are warranted.

Although PMN challenged with LPS increased $(P$ $\leq 0.01)$ the expression of some inflammatory genes (Supplemental Table S4; http://dx.doi.org/10.3168/ jds.2015-10086), it did not increase the production of TNF- $\alpha$ in media (Figure 1A) as previously observed in our laboratory (Garcia et al., 2015b) as well as in human studies (Cassatella et al., 1993). Neither the phagocytic nor the chemotactic capabilities of PMN in vitro were affected by LPS challenge. Moreover, LPS challenge did not affect concentrations of AA (Table 1) or their apparent utilization in media (Supplemental Table S5; http://dx.doi.org/10.3168/jds.2015-10086); however, the expression of SLC2A3, coding for the glucose transporter GLUT-3, was increased due to LPS challenge $(P=0.03, \mathrm{FC}=1.19)$. This was not reflected by an increase in apparent glucose utilization (data not shown). We also observed similar results in our previous study evaluating the effect of glucose on blood PMN (Garcia et al., 2015b), indicating that glucose and additional AA may not be the preferred fuel used by bovine blood PMN during the inflammatory response. The lack of effect of LPS on the expression of key genes involved in AA and glucose metabolism may indicate that Gln (not supplemented in the current pool of AA) may be the preferred AA for bovine PMN during the inflammatory response.

Regardless of LPS challenge and stage of lactation, AA supplementation may attenuate the inflammatory response of PMN by reducing $(P=0.01)$ the concentrations of TNF- $\alpha$ in spent media (109.2 vs. $35.5 \mathrm{pg} /$ $\mathrm{mL}$; Figure 1A) and by reducing the expression of several inflammatory genes. Among these inflammatory genes are those coding for signaling factors (NFKB1 and NFKBIA), proinflammatory cytokines (IL1B, IL6, and TNFA), and intracellular killing enzymes ( $L Y Z$ and SOD2). Interestingly, the expression of $I L 10$, the gene coding for the anti-inflammatory cytokine IL-10, also decreased $(P<0.01)$ due to AAS. However, neither PMN chemotaxis (69 vs. $67 \pm 11$ PMN cells migrating for CTL and AAS, respectively, $P=0.78$ ) nor phagocytosis (37.6 vs. $34.8 \pm 3.3 \%$ for CTL and AAS, respectively, $P=0.15)$ were altered by AA supplementation. Our results indicate that AA supplementation,

Table 2. Effect of the interaction of AA supplementation in vitro ${ }^{1}$ and stage of lactation on the concentration of AA in media $(\mu M)$ by PMN from Holstein cows in early $(\mathrm{n}=6)$ or mid lactation $(\mathrm{n}=6)$

\begin{tabular}{|c|c|c|c|c|c|c|}
\hline \multirow[b]{3}{*}{ Item } & \multicolumn{4}{|c|}{ Stage of lactation (SL) } & \multirow[b]{3}{*}{ SEM } & \multirow{3}{*}{$\frac{P \text {-value }}{\mathrm{AA} \times \mathrm{SL}}$} \\
\hline & \multicolumn{2}{|c|}{ Early } & \multicolumn{2}{|c|}{ Mid } & & \\
\hline & CTL & AAS & CTL & AAS & & \\
\hline \multicolumn{7}{|c|}{ Essential } \\
\hline Lys & $15.7^{\mathrm{c}}$ & $36.9^{\mathrm{b}}$ & $20.3^{\mathrm{c}}$ & $48.4^{\mathrm{a}}$ & 1.8 & 0.02 \\
\hline Met & $24.5^{\mathrm{c}}$ & $48.3^{\mathrm{b}}$ & $27.8^{\mathrm{c}}$ & $56.8^{\mathrm{a}}$ & 1.5 & 0.06 \\
\hline Thr & $43.1^{\mathrm{c}}$ & $103.3^{\mathrm{b}}$ & $50.2^{\mathrm{c}}$ & $120.7^{\mathrm{a}}$ & 4.1 & 0.10 \\
\hline \multicolumn{7}{|c|}{ Nonessential } \\
\hline Arg & $30.7^{\mathrm{c}}$ & $39.3^{\mathrm{b}}$ & $32.7^{\mathrm{c}}$ & $48.3^{\mathrm{a}}$ & 1.3 & $<0.01$ \\
\hline Asn & $2.4^{\mathrm{c}}$ & $18.4^{\mathrm{b}}$ & $4.1^{\mathrm{c}}$ & $25.1^{\mathrm{a}}$ & 1.4 & 0.04 \\
\hline Glu & $25.2^{\mathrm{c}}$ & $53.7^{\mathrm{b}}$ & $28.9^{\mathrm{c}}$ & $65.3^{\mathrm{a}}$ & 2.1 & 0.02 \\
\hline
\end{tabular}

${ }^{\mathrm{a}-\mathrm{c}}$ Within row and column, superscripts with different lowercase letters differ $(P \leq 0.05)$.

${ }^{1}$ Additional AA supplementation: CTL (no additional AA) or AAS (4 $\mathrm{m} M$ of a pool of additional AA without Gln) and LPS challenge: No LPS $(0 \mu \mathrm{g} / \mathrm{mL}$ of culture media) or LPS $(50 \mu \mathrm{g} / \mathrm{mL}$ of culture media) incubated for $2 \mathrm{~h}$. 
excluding Gln, may have anti-inflammatory properties. Glutamine is the preferred AA used by leukocytes for ATP synthesis via the Krebs cycle, cytokine production, phagocytosis, and reactive oxygen metabolite (Ingvartsen and Moyes, 2013), but little is known regarding the role of other AA with regards to PMN response during inflammation and how this response differs based on stage of lactation. Sipka et al. (2014) observed that 14 of the 21 supplemented AA, which included Gln, reduced oxidative response, whereas only supplemental Arg increased oxidative response of human PMN. This provides support to our results suggesting an anti-inflammatory mechanism of other AA rather than Gln on bovine blood PMN response.

Regarding alterations in the apparent utilization of glucose by AA supplementation, concentration of glu- cose in the spent media was greater $(P=0.02$, Figure 1B), resulting in a lower utilization $(P=0.02$, Figure $1 \mathrm{C})$ in the AAS when compared with the CTL. Our results indicate that AA supplementation may spare glucose for other processes in bovine blood PMN. This is supported by a greater $(P<0.01)$ AA concentration in spent media (1.50 vs. $2.88 \mu M)$ and greater apparent AA utilization (1.60 vs. $4.22 \mu M)$ for the AAS compared with the CTL group, as well as a lower expression of SLC2A3 (FC $=-1.23, P=0.01)$. However, we observed minimal changes in the expression of key genes associated with AA and glucose metabolism. For instance, the expression of genes coding for the enzymes branched-chain keto acid dehydrogenase E1 $(B C K D H B)$ and lactate dehydrogenase $\mathrm{A}(L D H A)$ and receptors (INSR) involved in glucose and AA metabo-
A

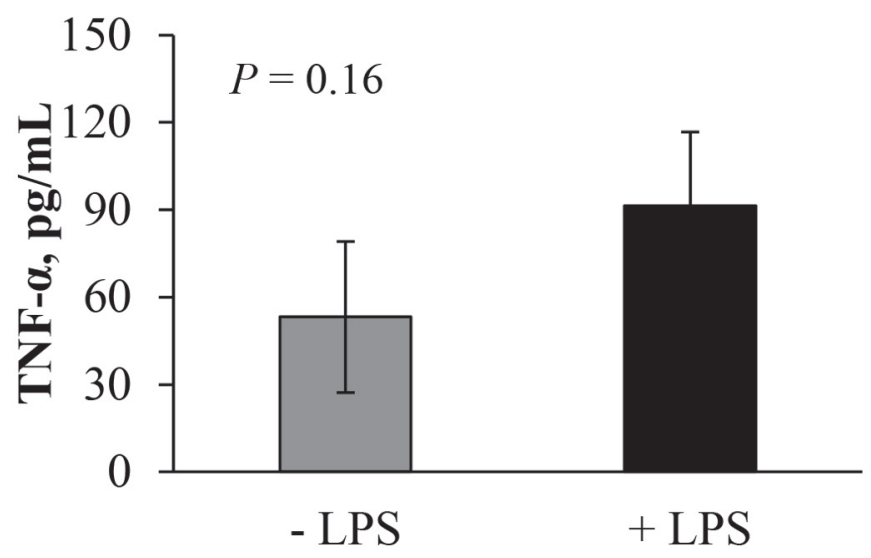

$\mathrm{C}$

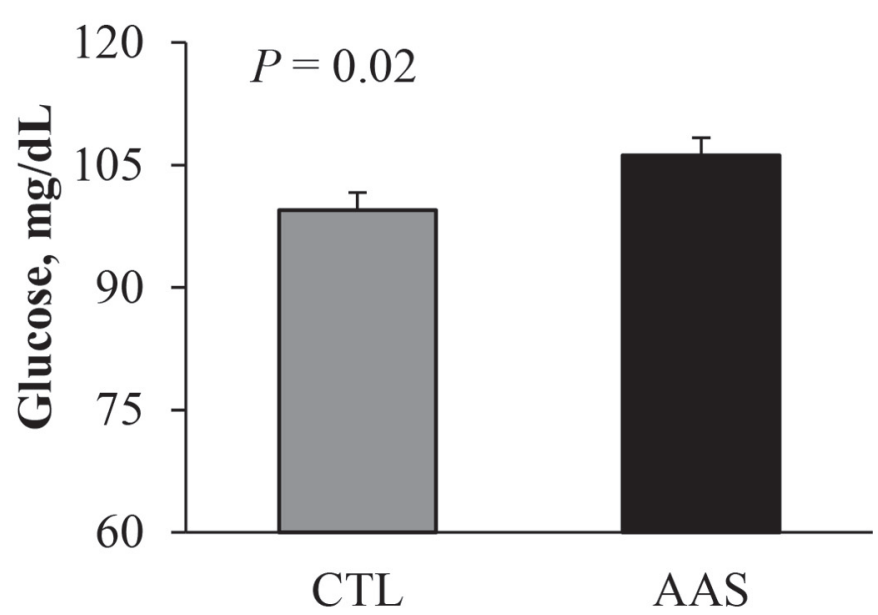

$\mathrm{B}$

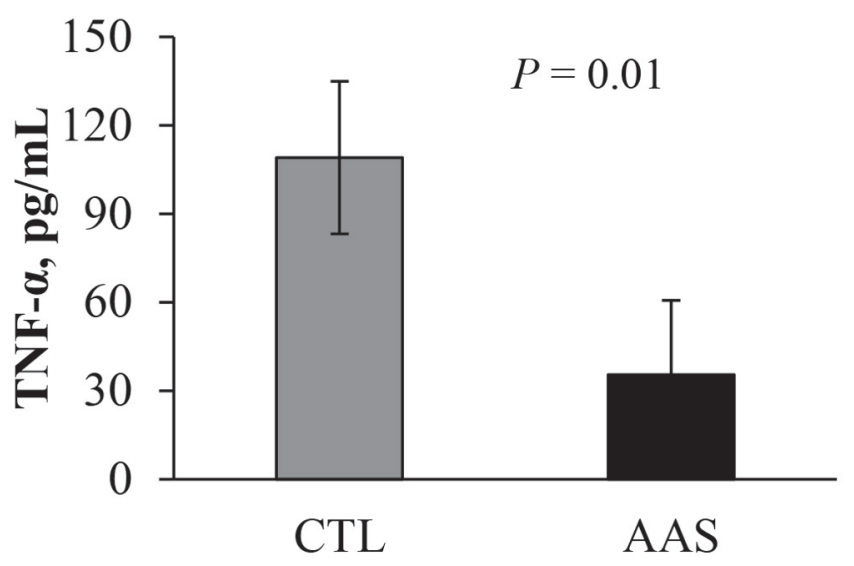

$\mathrm{D}$

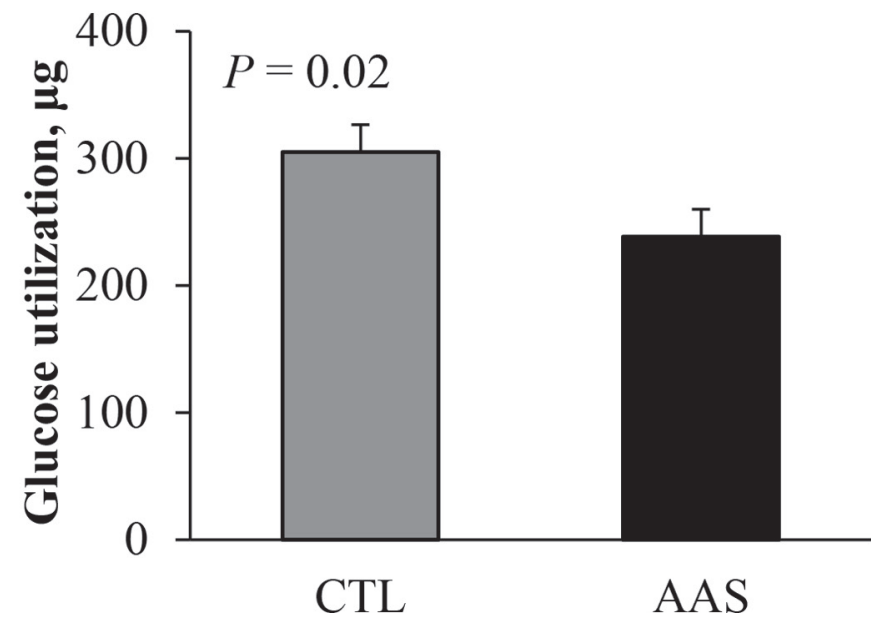

Figure 1. Effect of LPS challenge and AA supplementation on concentrations of tumor necrosis factor- $\alpha$ (TNF- $\alpha$; A and B, respectively), glucose concentration in spent media (C) and estimated glucose utilization (D). Polymorphonuclear leukocytes were incubated with (4 m $M$; AAS) or without $(0 \mathrm{mM}$; CTL) additional pool of AA, without Gln, and with $(50 \mu \mathrm{g} / \mathrm{mL}$ of culture media) or without $(0 \mu \mathrm{g} / \mathrm{mL}$ of culture media) LPS in vitro for $2 \mathrm{~h}$. Error bars represent SEM. 
lism were not altered by AA supplementation (Supplemental Table S4; http://dx.doi.org/10.3168/jds.201510086). However, the expression of G6PD, coding for the enzyme glucose 6-phosphate dehydrogenase, was increased $(\mathrm{FC}=1.29, P=0.05)$ and that of PDHA1, coding for the enzyme pyruvate dehydrogenase $\alpha 1$, tended $(\mathrm{FC}=1.40, P=0.09)$ to increase, whereas SLC2A3 (FC $=-1.23, P=0.01)$ was decreased for AAS when compared with CTL. The increased expression of G6PD and PDHA1 may indicate that the AAS group was able to produce intermediaries (i.e., ribose 5 phosphate) for the synthesis of reducing equivalents (i.e., NADPH) required for oxidative burst (Moyes, 2015), whereas the reduction in SLC2A3 expression may indicate increased availability of glucose for other metabolic or inflammatory processes. Our results suggest that bovine blood PMN may have the ability to shift the utilization of nutrients, such as from glucose to AA, depending on temporal availability, potentially sparing glucose for other processes within bovine blood PMN. Whether this response can be observed in vivo warrants further investigation.

As expected, AA supplementation increased $(P \leq$ 0.01) AA concentrations in media (Table 1). Apparent AA utilization was also greater in AAS when compared with CTL (Supplemental Table S5; http://dx.doi. org/10.3168/jds.2015-10086). However, for Ile, Ala, and Pro, AAS resulted in a greater release when compared with CTL, indicating an overall synthesis of Ile, Ala, and Pro. Mammals cannot synthesize the EAA Ile de novo, but may synthesize Ile from precursors; hence, the increased concentration of Ile was generated from precursors with similar structure (i.e., branched-chain AA Leu and Val; Reeds, 2000). Histidine and Trp (i.e., the AA with the lowest concentration before incubation) were not detected in the spent media, which indicates that these AA were used by bovine blood PMN. Alanine was not provided in the media but was present in spent media, indicating that Ala was released by bovine blood PMN and this response was enhanced $(P<0.01)$ by AAS when compared with CTL. The synthesis of Ala from other AA supplied may indicate that Ala serves as an important energy substrate for leukocytes (Li et al., 2007). With regard to utilization of AA by bovine blood PMN and regardless of treatments (i.e., AA supplementation, LPS, and stage of lactation), the EAA His and Trp were not detected in spent media, indicating their complete utilization by bovine blood PMN in vitro. The EAA Lys had the greatest $(P<0.05)$ apparent utilization $(89.9 \pm 6.2 \%)$ and the utilization of Leu, Met, Phe, and Thr did not differ $(P>0.10)$ in bovine blood PMN in vitro. For the nonessential AA, Arg and Asn had the greatest $(P$ $<0.05)$ apparent utilization, and this utilization was more pronounced in AAS than CTL (Asn $=98.8$ vs. $96.5 \%$ and $\operatorname{Arg}=95.8$ vs. $97.5 \%$, respectively). Valine was used the least $(P<0.05)$ by blood PMN, and this effect was more pronounced for CTL than AAS groups (4.1 vs. $54.0 \%$ for CTL and AAS, respectively). Besides Gln, Arg is another well-studied AA due to its important role in the inflammatory response of human PMN (Li et al., 2007; Wijnands et al., 2015). In the current study, Arg was offered in greater supply ( $25 \%$ of total supply) when compared with other supplemented AA and partly explains the greater utilization of Arg.

Due to the lower concentration of TNF- $\alpha$ in media coupled with a downregulation of several proinflammatory genes, we concluded that AA, Gln excluded, alter the inflammatory response of bovine blood PMN. In vitro challenge with LPS did not alter the expression of key genes involved in AA and glucose metabolism, suggesting that Gln may be the preferred AA for bovine PMN during the inflammatory response. Independent from Gln, blood PMN from cows in early lactation rather than late lactation may use certain AA as their primary carbon source for energy. This supports our previous results, where we concluded that blood PMN from cows in mid lactation might benefit more by carbons donated from glucose supplementation than cows in early lactation (Garcia et al., 2015b). To our knowledge, we are the first to show that uptake and utilization of AA is increased or modified in blood PMN for cows in early lactation when compared with cows in mid lactation. Most cows in early lactation are in an oxidative state (i.e., utilizing carbons from glucose and AA for the generation of energy to meet the demands for milk production); due to this oxidative state, it may seem logical that blood PMN may prefer carbons from AA rather than glucose during early lactation. Evaluating cows during the early postpartum period will provide additional information into the effect of stage of lactation and nutrient supplementation on PMN function.

\section{ACKNOWLEDGMENTS}

Funding for this study was from the University of Maryland ADVANCE Competitive Grants Program and the Maryland Agricultural Experiment Station. The authors acknowledge the USDA-ARS staff in Beltsville, Maryland, for their assistance with animal care and data collection.

\section{REFERENCES}

Burvenich, C., D. D. Bannerman, J. Lippolis, L. Peelman, B. Nonnecke, M. Kehrli Jr., and M. Paape. 2007. Cumulative physiological events influence the inflammatory response of the bovine udder 
to Escherichia coli infections during the transition period. J. Dairy Sci. 90(Suppl. 1):E39-E54.

Cassatella, M. A., L. Meda, S. Bonora, M. Ceska, and G. Constantin. 1993. Interleukin 10 (IL-10) inhibits the release of proinflammatory cytokines from human polymorphonuclear leukocytes. Evidence for an autocrine role of tumor necrosis factor and IL-1 beta in mediating the production of IL-8 triggered by lipopolysaccharide. J. Exp. Med. 178:2207-2211.

Chapinal, N., S. J. LeBlanc, M. E. Carson, K. E. Leslie, S. Godden, M. Capel, J. E. P. Santos, M. W. Overton, and T. F. Duffield. 2012. Herd-level association of serum metabolites in the transition period with disease, milk production, and early lactation reproductive performance. J. Dairy Sci. 95:5676-5682.

Garcia, M., T. Elsasser, D. Biswas, and K. M. Moyes. 2015a. The effect of citrus-derived oil on bovine blood neutrophil function and gene expression in vitro. J. Dairy Sci. 98:918-926.

Garcia, M., T. H. Elsasser, Y. Qu, X. Zhu, and K. M. Moyes. 2015b. Glucose supplementation has minimal effects on blood neutrophil function and gene expression in vitro. J. Dairy Sci. 98:6139-6150.

Graugnard, D. E., M. Bionaz, E. Trevisi, K. M. Moyes, J. L. SalakJohnson, R. L. Wallace, J. K. Drackley, G. Bertoni, and J. J. Loor. 2012. Blood immunometabolic indices and polymorphonuclear neutrophil function in peripartum dairy cows are altered by level of dietary energy prepartum. J. Dairy Sci. 95:1749-1758.

Hailemariam, D., R. Mandal, F. Saleem, S. M. Dunn, D. S. Wishart and B. N. Ametaj. 2014. Metabolomics approach reveals altered plasma amino acid and Sphingolipid profiles associated with pathological state in transition dairy cows. Curr. Metabolomics 2:184-195.

Healy, D. A., R. W. G. Watson, and P. Newsholme. 2002. Glucose, but not glutamine, protects against spontaneous and anti-Fas antibody-induced apoptosis in human neutrophils. Clin. Sci. 103:179189.

Ingvartsen, K. L. 2006. Feeding- and management-related disease in the transition cow: Physiological adaptation around calving and strategies to reduce feeding-related diseases. Anim. Feed Sci. Technol. 126:175-213.

Ingvartsen, K. L., and K. Moyes. 2013. Nutrition, immune function and health of dairy cattle. Animal 7:112-122.

Kehrli, M. E., Jr., and D. E. Shuster. 1994. Factors affecting milk somatic cells and their role in health of the bovine mammary gland. J. Dairy Sci. 77:619-627.

Li, P., Y. L. Yin, D. F. Li, S. W. Kim, and G. Wu. 2007. Amino acids and immune function. Br. J. Nutr. 98:237-252.

Livak, K. J., and T. D. Schmittgen. 2001. Analysis of relative gene expression data using real-time quantitative PCR and the 2(-Delta Delta C(T)) method. Methods 25:402-408.
Maeda, Y., H. Ohtsuka, and M. Oikawa. 2012. Effect of the periparturient period on blood free amino acid concentration in dairy cows/ healthy cows. J. Vet. Med. Anim. Health. 4:124-129.

Meijer, G. A. L., J. Van der meulen, J. G. M Bakker, C. J. Van der koelen, and A. M. Van Vuuren. 1995. Free amino acids in plasma and muscle of high yielding dairy cows in early lactation. J. Dairy Sci. 78:1131-1141.

Moyes, K. M. 2015. Nutrient partitioning during intramammary inflammation: A key to severity of mastitis and risk of subsequent disease? J. Anim. Sci. 93:5586-5593.

Ospina, P. A.. D. V. Nydam, T. Stokol, and T. R. Overton. 2010. Evaluation of non-esterified fatty acids and $\beta$-hydroxybutyrate in transition dairy cattle in the northeastern United States: Thresholds for prediction of clinical diseases. J. Dairy Sci. 93:546-554.

Perez-Carbajal, C., D. Caldwell, M. Farnell, K. Stringfellow, S. Pohl, G. Casco, A. Pro-Martinez, and C. A. Ruiz-Feria. 2010. Immune response of broiler chickens fed different levels of arginine and vitamin E to a coccidiosis vaccine and Eimeria challenge. Poult. Sci. 89:1870-1877.

Pohlenz, C., A. Buentello, W. Mwangi, and D. M. Gatlin III. 2012. Arginine and glutamine supplementation to culture media improves the performance of various channel catfish immune cells. Fish Shellfish Immunol. 32:762-768.

Reeds, P. J. 2000. Dispensable and indispensable amino acids for humans. J. Nutr. 130:1835S-1840S.

Revelo, X. S., and M. R. Waldron. 2012. In vitro effects of Escherichia coli lipopolysaccharide on the function and gene expression of neutrophils isolated from the blood of dairy cows. J. Dairy Sci. 95:2422-2441.

SAS Institute. 2009. SAS/STAT 9.2 User's Guide. SAS Inst. Inc., Cary NC.

Sipka, S., T. Keresztes, I. Kovács, S. Sipka Jr., S. Baráth, G. Szegedi, M. Zeher, and G. Bruckner. 2014. Effects of L-amino acids on human peripheral neutrophil granulocyte activation. Open Nutr. J. $8: 1-7$.

Tan, B., X. G. Li, X. F. Kong, R. Huang, Z. Ruan, K. Yao, Z. Deng, M. Xie, I. Shinzato, Y. Yin, and G. Wu. 2009. Dietary L-arginine supplementation enhances the immune status in early-weaned piglets. Amino Acids 37:323-331.

Weekes, T. L., P. H. Luimes, and J. P. Cant. 2006. Responses to amino acid imbalances and deficiencies in lactating dairy cows. J. Dairy Sci. 89:2177-2187.

Wijnands, K. A. P., T. M. R. Castermans, M. P. J. Hommen, D. M. Meesters, and M. Poeze. 2015. Arginine and citrulline and the immune response in sepsis. Nutrients 7:1426-1463. 